\title{
CONSUMO DA CIRURGIA PLÁSTICA ATRAVÉS DA VAIDADE
}

Consumption of plastic surgery through vanity

\section{Juliana Cristina das Chagas de Melo ${ }^{1}$ \\ Maria Helena Moraes Batista ${ }^{2}$ \\ Alisson Henrique dos Santos Rosendo ${ }^{3}$ \\ Salomão Alencar de Farias ${ }^{4}$}

RESUMO: A vaidade, um dos sete pecados capitais do catolicismo, apresenta-se como uma das influências no comportamento do consumidor de cirurgias plásticas. Dentro desse contexto, o presente artigo traz uma discussão acerca da influência da vaidade no consumo, destacando inicialmente definições da vaidade em diferentes abordagens, dando suporte ao entendimento de que ela está relacionada com a aparência que o indivíduo apresenta à sociedade. Tendo em vista o significado do corpo frente à decisão de fazer uma cirurgia plástica, levanta-se a questão da influência da mídia sobre o corpo, já que este compreende a aparência da pessoa. Ademais, ressalta-se que a mídia dita padrões de beleza nos quais os indivíduos gostariam de se inserir. Através disso, as pessoas decidem fazer intervenções para adequar-se ao biótipo “ideal”. Efeitos do envelhecimento ou aspectos do corpo que não agradem a pessoa também agem como influenciadores em intervir cirurgicamente para ter a aparência desejada frente à sociedade. Através desta relação mídia - padrões de beleza - corpo - vaidade, tem-se a compreensão de que esta temática se torna relevante aos estudos que envolvam consumo e sociedade, tendo em vista que o consumo simbólico, conspícuo, o self estendido e o materialismo estão presentes nesta discussão.

PALAVRAS-CHAVE: consumo; vaidade; cirurgia plástica.

ABSTRACT: Vanity, one of the seven deadly sins of Catholicism, is one of the influences on consumer behavior in plastic surgery. Within this context, the present article brings up a discussion about the influence of vanity on consumption, highlighting initially definitions of vanity in different approaches, supporting the understanding that it is related to the appearance that the individual presents to society. Considering the meaning of the body in relation to the decision to perform plastic surgery, the question arises of the influence of the media on the body, since it understands the appearance of the person. In addition, it is emphasized that the media

\footnotetext{
${ }^{1}$ Mestranda em Consumo, Cotidiano e Desenvolvimento Social na UFRPE

${ }^{2}$ Especialista em MBA Executivo em Gestão Estratégica de Marketing pelo Fundação de Apoio ao

Desenvolvimento da Universidade Federal de Pernambuco (2015)

${ }^{3}$ Mestrando em Consumo, Cotidiano e Desenvolvimento Social na UFRPE

${ }^{4}$ Professor Associado da UFPE
} 
dictates beauty standards in which individuals would like to insert themselves. Through this, they decide to make interventions to fit the "ideal" biotype. Effects of aging or aspects of the body that do not delight the person also act as influencers in intervening surgically to have the desired appearance in front of society. Through this relationship media - beauty - body - vanity patterns, one has the understanding that this theme becomes relevant to studies that involve consumption and society, considering that symbolic consumption, conspicuous, extended self and materialism are present in this discussion.

KEY WORDS: consumption; vanity; plastic surgery.

\section{INTRODUÇÃO: A INFLUÊNCIA DA VAIDADE NO CONSUMO}

Desde os primórdios a beleza e a boa forma tem sido sinônimos de preocupação, de modo que em cada época havia um estereotipo ideal de beleza. Paralelo à construção de padrões de boa forma e beleza, há uma ideologia política, elitista e social, tendo em vista que a estética corporal atua como divisor social quando exclui os que não estão de acordo com os arquétipos difundidos pelos meios de comunicação. (FLOR, 2009) ${ }^{1}$

Quando em excesso, os cuidados com o corpo e a beleza são chamados de "vaidade". Considerada com um dos sete pecados capitais do catolicismo, a vaidade pode assumir conotação negativa em relação às virtudes morais, como uma espécie de vício ou arrogância depreciadora. (STREHLAU, Et al., 2010) ${ }^{2}$. Para alguns filósofos, a vaidade tem diferentes conceitos. Para o filósofo Aristóteles, a vaidade se conceitua como o extremo das virtudes humanas, o que seria um grande impedimento para o homem alcançar a felicidade (SILVEIRA, 2000) ${ }^{3}$. Para Jean Jacques Rousseau, a sua teoria de reconhecimento tinha como base o amor próprio que sustentava a ideia de vida em sociedade por relações com o outro por superioridade e valor humano muitas vezes através da vaidade (DENT, 1996) ${ }^{4}$. Para o brasileiro Matias Aires da Silva de Eça (1705-63) ${ }^{1}$ :

\footnotetext{
1 FLOR, Gisele. Corpo, mídia e status social: reflexões sobre os padrões de beleza. Revista de Estudos da Comunicação., Curitiba, v. 10, n. 23, 2009. p. 267-274, set./dez.

2 STREHLAU, Vivian Iara., CLARO, Danny Pimentel., NETO, Silvio Abrahão Laban. Espelho, espelho meu, existe alguém mais vaidosa do que eu? A vaidade feminina e sua influência na autoestima e no consumo de procedimentos estéticos. IV Encontro de Marketing da Anpad. Florianópolis / SC - maio de 2010.

${ }^{3}$ SILVEIRA, Denis. As virtudes em Aristóteles. Revista de Ciências Humanas, v.1, n.1, 2000, p. 41-71, Editora da Uri.
}

${ }^{4}$ DENT, Nicholas J. H. Dicionário Rousseau. Rio de Janeiro: Jorge Zahar, 1996. 
A imaginação desperta e dá movimento à vaidade; por isso esta não é paixão do corpo, mas da alma. Não é vício da vontade, mas do entendimento, pois depende do discurso. Daqui vem que a mais forte e a mais vã de todas as vaidades. É a que resulta do saber, porque no homem não há pensamento que mais o agrade do que aquele que o representa superior aos mais e superior no entendimento que é nele a parte mais sublime.

$\mathrm{Na}$ visão de Matias Aires, o homem é corruptível e mau por natureza tendo motivação constante de satisfazer suas necessidades e desejos pessoais de forma egoísta (PINTO, 2003)².

Para Abdala (2008) ${ }^{3}$ a vaidade faz parte da constituição da cultura da humanidade, sendo um tema universal, normalmente compreendido como uma visão exagerada de si, uma afirmação esnobe de autoestima, poder e beleza. O autor afirma ainda que a vaidade está relacionada a diversos conceitos do comportamento do consumo, tais como, o consumo simbólico, conspícuo, o self estendido e o materialismo.

Nos tempos de uma sociedade globalizada os indivíduos buscam construir sua própria identidade a partir de padrões ditados pela cultura de massa onde o mais importante não é o ser, ou mesmo o ter, mas o parecer ser (BAUMAN, 2001) ${ }^{4}$. Na construção desta identidade, a aparência física é um dos mais importantes fatores que tem sido muito explorado pela indústria da beleza, uma vez que a sociedade desempenha comportamentos diferenciados para aqueles que possuem atributos de beleza física (DION, BERSCHEID, WALSTER, 1972) ${ }^{5}$.

\section{COMPORTAMENTO DO CONSUMIDOR, CIRURGIA PLÁSTICA E VAIDADE}

$\mathrm{Na}$ pós-modernidade, a sociedade vive tempos de transformações culturais globalizadas e caracterizadas pelo individualismo, neo-narcisismo, estetização, simbolismo, desenfreado

\footnotetext{
${ }^{1}$ EÇA, Matias Aires da Silva de. Reflexões Sobre a Vaidade dos Homens. Introdução de A. Amoroso Lima. São Paulo: Martins Fontes, 1993.

2 PINTO, Paulo Roberto Margutti. Reflexões sobre a vaidade dos homens: Hume e Matias Aires. Kriterion, vol.44, no 108,2003, p.253-278.

${ }^{3}$ ABDALA, Paulo Ricardo Zilio. Vaidade e Consumo: como a vaidade física influencia o comportamento do consumidor. 2008. Dissertação (Mestrado em Administração) - Escola de Administração - Universidade Federal do Rio Grande do Sul - RS.

${ }^{4}$ BAUMAN, Zygmunt. Modernidade Líquida. Rio de Janeiro: Jorge Zahar, 2001.

${ }^{5}$ DION, Karen, BERSCHEID, Ellen \& WALSTER, Elaine. What is beautiful is good. Journal of Personality and Social Psychology, v24, n.3, p. 285-290, 1972.
} 
consumismo hedônico, desigualdade social e econômica e imediatismo (AGOSTINI, 2008) ${ }^{1}$. Diante desse contexto, consideramos o que afirma Lipovetsky $(1989)^{2}$ :

Com o culto da beleza feminina e o repúdio da imagem da mulher como agente de Satã, o desejo feminino de embelezar-se, de agradar, vai poder adquirir uma profunda legitimidade social. Por isso, as sociedades modernas repousam não apenas no princípio de igualdade entre os sexos, mas também no princípio não igualitário do "belo sexo": a beleza permanece um atributo, um valor particular do feminino, é admirada, encorajada, exibida em profusão entre as mulheres, pouco entre os homens.

$\mathrm{Na}$ sociedade moderna iniciou-se um movimento imperativo da beleza feminina com celebridades ícones de beleza física. A partir de então, iniciou-se a mercantilização do consumo em massa de produtos e serviços na perspectiva de satisfazer o desejo de alcance de um ideal de beleza e de autoestima.

A preocupação com o enquadramento nos padrões da moda sempre fizeram parte do comportamento humano como forma de pertencimento destacado em sociedade. Estes padrões tendem a copiar modelos ditos por sociedades de países economicamente desenvolvidos. No livro Modos de homem, modas de mulher do pernambucano Gilberto Freyre $(1987)^{3}$, afirmava que:

Pode-se dizer da mulher que tende a ser, quanto a modas para seus vestidos, seus sapatos, seus penteados, um tanto maria-vai-com-as-outras. Portanto, a corresponder ao que a moda tem de uniformizante. Mas é da argúcia feminina a iniciativa de reagir contra essa uniformização absoluta de acordo com características pessoais que não se ajustem a imposições de uma moda disto ou daquilo. Neste particular, é preciso reconhecer-se, na brasileira morena, o direito de repudiar modas norte-européias destinadas a mulheres louras e alvas (Freyre, 1987: 33).

No Brasil, por muitos anos a representação de beleza feminina foi vinculada à mulher de pele morena, cabelos negros, longos e crespos, cintura fina, bunda grande e peitos pequenos. Com o passar das últimas décadas, estas características sofreram influências dos padrões de beleza importados de países caucasianos estimulando, através da mídia comercial, as mulheres brasileiras de diversas etnias a desejarem ser iguais às celebridades que diferenciavam por completo do seu biótipo (GOLDENBERG, 2005) ${ }^{4}$. A aparência física nunca foi tão cultuada

\footnotetext{
1 AGOSTINI, Frei Nilo. Pós-Modernidade e o Ser Humano. Revista de Cultura Teológica, no 63, 2008, p.113126.

${ }^{2}$ LIPOVETSKI, Gilles. O império do efêmero: A moda e seu destino nas sociedades modernas. Companhia das Letras, 1989.

${ }^{3}$ FREYRE, Gilberto. Modos de homem, modas de mulher. Rio de Janeiro: Record, 1987.

${ }^{4}$ GOLDENBERG, Miriam. Gênero e corpo na cultura brasileira. Psicologia Clínica: v.17, n.2, 2005, p.65 -80. Rio de Janeiro.
} 
pelas pessoas que buscam cada vez mais se autoafirmarem em seu meio por necessidades físicas, de segurança ou autoestima.

\section{O CORPO E CIRURGIAS PLÁSTICAS}

Para Ribeiro (2003) ${ }^{1}$, através do corpo é possível observar o sujeito contemporâneo, não tratando-o como objeto, mas como um sujeito de sensações e experiências, transmitindo a visibilidade do ser. Antônio $(2008)^{2}$ considera que o culto à aparência e à forma física exige autocontrole dos indivíduos no tocante a força de vontade e disciplina na obtenção do corpo "trabalhado" e definido.

Castro $(2010)^{3}$ considera o corpo como a expressão da sociedade e dos modos de vida cotidianos, ao passo que, os hábitos adotados sob o mesmo, bem como os padrões que definem sua normalidade e aceitação, representam a organização social na qual ele está inserido. A autora ainda acrescenta que a preocupação com a aparência, está ligada à modernidade, de modo que os indivíduos necessitam definir suas identidades.

De acordo com Mélo (2006) ${ }^{4}$, o corpo deve ser considerado além de sua estrutura orgânica, o que o torna interessante a partir das expectativas criadas em torno da corporeidade, representando o que pode ser transformado através de técnicas que se constroem pela busca da beleza. Diante disto, é aprendido o que se fazer com o corpo, indo desde rituais de beleza mais simples até as cirurgias, demonstrando que, embora a constituição biológica também seja uma constituinte, deve-se levar em conta os elementos culturais envolvidos na apresentação corporal.

Atualmente as expectativas de modificação do corpo possuem grandes proporções ao passo que há uma grande procura em busca de intervenções estéticas, tanto em suas formas

\footnotetext{
${ }^{1}$ RIBEIRO, Liliane. Brum. Cirurgia Plástica estética em corpos femininos: a medicalização da diferença. In: V Reunião de Antropologia do Mercosul: Antropologia em Perspectivas, 2003, Florianópolis. V Reunião de Antropologia do Mercosul: Antropologia em Perspectivas. Florianópolis: Universidade Federal de Santa Catarina, 2003. v. 1. p. 239-240.

2 ANTÔNIO, Andrea Tochio de. Corpo e Estética: um estudo antropológico de cirurgia plástica. 2008. Dissertação (Mestrado em Antropologia Social) - Instituto de Filosofia e Ciências Humanas - Universidade Estadual de Campinas. Campinas - SP.

${ }^{3}$ CASTRO, Ana Lúcia de. Corpos ciborgues, identidade e cirurgia plástica como consumo cultural. In.: CASTRO, AL., org. Cultura contemporânea, identidades e sociabilidades: olhares sobre corpo, mídia e novas tecnologias [online]. São Paulo: Editora UNESP - Cultura Acadêmica, 2010, p. 151 - 166.

4 MÉLO, Roberta de Sousa. Admirável corpo novo: cirurgia plástica e reconfiguração corporal. 2006. Dissertação (Mestrado em Sociologia). Centro de Filosofia e Ciências Humanas - Universidade Federal de Pernambuco - Recife - PE.
} 
tradicionais como também procedimentos que necessitem de mais aparato tecnológico, que carregam em si um discurso de realização de desejos. Paralelamente, a contemporaneidade traz consigo uma discussão que promove substituir o corpo natural pelo corpo de consumo, de modo que este seja controlado, entrando no mercado com a capacidade de consumir, ser consumido e remodelado, ou seja, qualquer pessoa pode investir simbolicamente em seu corpo, clareando, bronzeando, esticando, aumentando ou diminuindo. (MÉLO, 2006)

O corpo torna-se uma matéria flexível, moldável às expectativas pessoais. No ponto de vista de cirurgias plásticas, esta pode ser vista como um projeto corporal, tendo em vista que pode ser realizado em etapas, podendo ser refeito, levando em consideração a noção fragmentária do mesmo. (ANTÔNIO, 2008)

No Brasil, as cirurgias plásticas já fazem parte do cotidiano, construindo um ideal de beleza moderno associados às outras técnicas de definição do corpo. São sempre desenvolvidas novas descobertas e métodos, marcados por cortes pequenos, minimização da dor e cicatrização perfeita. Uma das condições das cirurgias plásticas é promover a subjetivação de uma experiência baseada em padrões estéticos do coletivo, baseados em corpo perfeito e formas ideais, configurando-se como uma tentativa de fugir das marcas do tempo e modificar aquilo que a natureza atua - ou deixou de atuar, criando um novo corpo. (RIBEIRO, 2003) ${ }^{1}$.

De acordo com a Sociedade Brasileira de Cirurgias Plásticas (SBCP), foram realizadas 23 milhões de cirurgias plásticas no mundo no ano de 2013, dos quais 1.491 .721 foram feitas no Brasil classificando o país como o primeiro na posição do ranking mundial ficando à frente dos Estados Unidos, México, Alemanha e Espanha (SBCP, 2014)². Ainda segundo esta pesquisa, os Estados Unidos lideram o primeiro lugar quando se contabiliza procedimentos cirúrgicos como cirurgias plásticas e não cirúrgicos estéticos. Dentre os procedimentos cirúrgicos, os mais procurados nas clínicas médicas brasileiras são a mamoplastia, lipoaspiração, rinoplastia e abdominoplastia. Dentre os procedimentos não cirúrgicos, o mais procurado pelas mulheres é a aplicação da toxina botulínica, mais conhecido como preenchimento de rugas com uso de Botox.

\footnotetext{
${ }^{1}$ RIBEIRO, Liliane. Brum. Cirurgia Plástica estética em corpos femininos: a medicalização da diferença. In: V Reunião de Antropologia do Mercosul: Antropologia em Perspectivas, 2003, Florianópolis. V Reunião de Antropologia do Mercosul: Antropologia em Perspectivas. Florianópolis: Universidade Federal de Santa Catarina, 2003. v. 1. p. 239-240.

25ociedade Brasileira de Cirurgia $\quad$ Plástica $\quad$ (SBCP).

De acordo com a ISAPS, Brasil lidera ranking de cirurgias plásticas no mundo. Disponível em: <http://www2.cirurgiaplastica.org.br/de-acordo-com-a-isaps-brasil-lidera-ranking-de-cirurgias-plasticas-nomundo>. Último acesso em: 10 de julho de 2017.
} 
Dentro de um contexto da compreensão das relações entre consumo e construção das identidades na cultura contemporânea, Castro (2010) considera que as cirurgias plásticas (mais procuradas por mulheres do que por homens), se configuram como um consumo cultural, expresso através das formas mais evidentes e radicais de executar um projeto corporal.

Partindo desse ponto de vista, Antônio (2008) considera que as cirurgias plásticas, configuram-se através de técnicas de intervenção corporal associadas a valores, padrões comportamentais e estéticos, de modo que a operacionalização médico-terapêutica está relacionada em manter a autoestima sempre elevada.

Em análise sobre o comportamento do consumidor do universo do culto à beleza, destacam-se os principais motivos pelos quais os consumidores buscam alterar, restaurar ou aperfeiçoar partes do seu corpo: a grande preocupação de sua autoimagem e alta valorização da aparência externa que tem como características de personalidade a vaidade e o narcisismo, mais predominante em mulheres brancas do que em mulheres de outros grupos étnicos como asiáticas, negras ou latinas (DELINSKY, 2005) ${ }^{1}$. Na decisão de realizar procedimentos cirúrgicos, as mulheres desejam alcançar objetivos como reduzir efeitos do envelhecimento, corrigir defeitos físicos e esculpir um corpo perfeito, sendo este último ponto o maior motivo pelos quais as consumidoras lotam as clínicas médicas (GOLDENBERG, 2005).

\section{A INFLUÊNCIA DA MÍDIA EM RELAÇÃO AO CORPO}

Os meios de comunicação vêm se apresentando como um importante veículo de divulgação e construção de padrões de beleza e exclusão social, de modo que para ser belo é preciso ter o corpo perfeito e todo sacrifício é válido para obtê-lo. Para tanto, é necessário gastar dinheiro e tempo. (FLOR, 2009)

A atuação da mídia se dá através da veiculação diária aos consumidores de dietas, cosméticos e procedimentos cirúrgicos de última geração, de modo que o mercado apresenta e incentiva ao consumidor a esculpir seu corpo de acordo com a imagem corporal valorizada atualmente. Os padrões específicos de beleza são propagados pela mídia, a exemplo, magreza, juventude, pele clara, cabelos compridos, cintura fina entre outros. (BACELLAR \& MARQUES, $2009)^{2}$

\footnotetext{
${ }^{1}$ DELINSKY, Sherrie Selwyn. Cosmetic Surgery: A Common and Accepted Form of Self-Improvement. Journal of Applied Social Psychology, 2005.

2 BACELlAR, Fátima C. T.; MARUES, Fernanda D. C. Impacto da Vaidade Física no Comportamento de Consumo. Revista Carioca de Produção, v. 2009, p. 1-11, 2009.
} 
Para Mélo (2006) ${ }^{1}$ um dos grandes sustentáculos do culto ao corpo é a mídia, de modo que exalta modelos de realização, sucesso e felicidade. E diante desse contexto, a cirurgia estética apresenta-se como um meio de adequação do indivíduo às exigências sociais contemporâneas. $\mathrm{O}$ receio à degeneração física e o desejo para eliminar características estéticas desagradáveis aumentam em grandes proporções a procura por procedimentos cirúrgicos.

Antônio (2008) afirma que o papel da mídia se determina por meio da propagação de valores e atributos vinculados ao padrão estético de beleza, com ênfase no corpo belo e magro e modelação da aparência.

Dentro desse contexto, o corpo medicalizado configurou-se a partir de um processo histórico e cultural ao passo que a mídia reforça sempre a procura pelas cirurgias plásticas. Além disso, o prestígio a cirurgiões plásticos brasileiros é destaque mundial, com destaque para Ivo Pitanguy, que declara ter operado pessoas famosas internacionalmente, mas que também se orgulha de seus clientes englobarem diversas classes sociais. (RIBEIRO, 2003) ${ }^{2}$

\section{CONSIDERAÇÕES FINAIS}

Em um de seus aspectos, a vaidade caracteriza-se pelos cuidados em excesso com o corpo, numa relação estreita entre autoestima, poder e beleza. Tendo em vista que a aparência pessoal está relacionada à construção da identidade, ela torna-se um dos principais alvos da indústria da beleza que, paralelo aos diversos tipos de mídia, configuram-se como as principais influências para a decisão de fazer uma intervenção no corpo.

Ao considerar a aparência corporal como um identificador pessoal, o indivíduo torna-se vulnerável ao que é exposto na mídia, tendo em vista que esta promove um padrão de beleza que, por vezes, é diferente da maioria das pessoas. Desta forma, a possibilidade de fazer uma cirurgia plástica torna-se a chance de incluir-se ao padrão dito como ideal, já que a sociedade desenvolve condutas diferentes para quem está fora do padrão "normal".

Não apenas a influência da mídia, mas também o desejo pessoal de se sentir incluído/a no padrão "ideal" move os indivíduos a intervirem esteticamente em seu corpo - em sua maioria,

\footnotetext{
1 MÉLO, Roberta de Sousa. Admirável corpo novo: cirurgia plástica e reconfiguração corporal. 2006. Dissertação (Mestrado em Sociologia). Centro de Filosofia e Ciências Humanas - Universidade Federal de Pernambuco - Recife - PE.

2 RIBEIRO, Liliane. Brum. Cirurgia Plástica estética em corpos femininos: a medicalização da diferença. In: V Reunião de Antropologia do Mercosul: Antropologia em Perspectivas, 2003, Florianópolis. V Reunião de Antropologia do Mercosul: Antropologia em Perspectivas. Florianópolis: Universidade Federal de Santa Catarina, 2003. v. 1. p. 239-240.
} 
mulheres. Consequências do envelhecimento e "defeitos" físicos (formas do corpo que para a pessoa não se apresenta como seu ideal de desejo) também movem o "querer" uma cirurgia plástica, destacando o corpo não apenas como matéria orgânica, mas também como a representação do eu ideal.

A partir daí, a substituição do corpo natural pelo corpo de consumo passa a ser controlada de tal forma que o indivíduo entre no mercado com a capacidade de consumir, ser consumido e remodelado, ou seja, investindo simbolicamente em seu corpo e moldando-o de acordo com suas expectativas pessoais.

Destaca-se também o fato de que a operacionalização médica se apresenta como uma intervenção que envolve valores, padrões comportamentais e estéticos que promovem a autoestima, mantendo-a sempre em alta, tendo em vista que a cirurgia plástica irá atender as ao que a pessoa espera tornar-se fisicamente.

Levando em consideração a perspectiva do comportamento do consumidor, é possível identificar a relação que há entre a vaidade e a decisão em fazer uma cirurgia plástica, tendo em vista que esta relaciona-se com o consumo simbólico, conspícuo, o self estendido e o materialismo. Sendo assim, esta discussão explora campos de estudos que perpassam por diversas áreas e pode contribuir ricamente para os estudos do consumo que estejam relacionados com diversos aspectos existentes entre a sociedade e a mídia.

\section{REFERÊNCIAS BIBLIOGRÁFICAS}

ABDALA, Paulo Ricardo Zilio. Vaidade e Consumo: como a vaidade física influencia o comportamento do consumidor. 2008. Dissertação (Mestrado em Administração) - Escola de Administração - Universidade Federal do Rio Grande do Sul - RS.

AGOSTINI, Frei Nilo. Pós-Modernidade e o Ser Humano. Revista de Cultura Teológica, no 63, 2008, p.113-126.

ANTÔNIO, Andrea Tochio de. Corpo e Estética: um estudo antropológico de cirurgia plástica. 2008. Dissertação (Mestrado em Antropologia Social) - Instituto de Filosofia e Ciências Humanas - Universidade Estadual de Campinas. Campinas - SP.

BACELLAR, Fátima C. T.; MARUES, Fernanda D. C. Impacto da Vaidade Física no Comportamento de Consumo. Revista Carioca de Produção, v. 2009, p. 1-11, 2009.

BAUMAN, Zygmunt. Modernidade Líquida. Rio de Janeiro: Jorge Zahar, 2001. 
CASTRO, Ana Lúcia de. Corpos ciborgues, identidade e cirurgia plástica como consumo cultural. In.: CASTRO, AL., org. Cultura contemporânea, identidades e sociabilidades: olhares sobre corpo, mídia e novas tecnologias [online]. São Paulo: Editora UNESP - Cultura Acadêmica, 2010, p. 151 - 166.

DELINSKY, Sherrie Selwyn. Cosmetic Surgery: A Common and Accepted Form of Selflmprovement. Journal of Applied Social Psychology, 2005.

DENT, Nicholas J. H. Dicionário Rousseau. Rio de Janeiro: Jorge Zahar, 1996.

DION, Karen, BERSCHEID, Ellen \& WALSTER, Elaine. What is beautiful is good. Journal of Personality and Social Psychology, v24, n.3, p. 285-290, 1972.

EÇA, Matias Aires da Silva de. Reflexões Sobre a Vaidade dos Homens. Introdução de A. Amoroso Lima. São Paulo: Martins Fontes, 1993.

FLOR, Gisele. Corpo, mídia e status social: reflexões sobre os padrões de beleza. Revista de Estudos da Comunicação., Curitiba, v. 10, n. 23, 2009. p. 267-274, set./dez.

FREYRE, Gilberto. Modos de homem, modas de mulher. Rio de Janeiro: Record, 1987.

GOLDENBERG, Miriam. Gênero e corpo na cultura brasileira. Psicologia Clínica: v.17, n.2, 2005, p.65 -80. Rio de Janeiro.

LIPOVETSKI, Gilles. O império do efêmero: A moda e seu destino nas sociedades modernas. Companhia das Letras, 1989.

Os tempos hipermodernos. São Paulo: Editora Barcarolla, 2004.

MÉLO, Roberta de Sousa. Admirável corpo novo: cirurgia plástica e reconfiguração corporal. 2006. Dissertação (Mestrado em Sociologia). Centro de Filosofia e Ciências Humanas Universidade Federal de Pernambuco - Recife - PE.

PINTO, Paulo Roberto Margutti. Reflexões sobre a vaidade dos homens: Hume e Matias Aires. Kriterion, vol.44, no 108, 2003, p.253-278.

RIBEIRO, Liliane. Brum. Cirurgia Plástica estética em corpos femininos: a medicalização da diferença. In: V Reunião de Antropologia do Mercosul: Antropologia em Perspectivas, 2003, 
Florianópolis. V Reunião de Antropologia do Mercosul: Antropologia em Perspectivas. Florianópolis: Universidade Federal de Santa Catarina, 2003. v. 1. p. 239-240.

SILVEIRA, Denis. As virtudes em Aristóteles. Revista de Ciências Humanas, v.1, n.1, 2000, p. 41-71, Editora da Uri.

Sociedade Brasileira de Cirurgia Plástica (SBCP). (2014). De acordo com a ISAPS, Brasil lidera ranking de cirurgias plásticas no mundo. Disponível em: $\quad<$ http://www2.cirurgiaplastica.org.br/de-acordo-com-a-isaps-brasil-lidera-ranking-decirurgias-plasticas-no-mundo>. Último acesso em: 10 de julho de 2017.

STREHLAU, Vivian Iara., CLARO, Danny Pimentel., NETO, Silvio Abrahão Laban. Espelho, espelho meu, existe alguém mais vaidosa do que eu? A vaidade feminina e sua influência na autoestima e no consumo de procedimentos estéticos. IV Encontro de Marketing da Anpad. Florianópolis / SC - maio de 2010. 